\title{
Youth and Online News: Reflections and Perspectives
}

\section{Citation}

Sandra Cortesi \& Urs Gasser, eds., Youth and Online News: Reflections and Perspectives (Berkman Center Research Publication No. 2015-3, Feb. 17, 2015).

\section{Permanent link}

http://nrs.harvard.edu/urn-3:HUL.InstRepos:16140638

\section{Terms of Use}

This article was downloaded from Harvard University's DASH repository, and is made available under the terms and conditions applicable to Open Access Policy Articles, as set forth at http:// nrs.harvard.edu/urn-3:HUL.InstRepos:dash.current.terms-of-use\#OAP

\section{Share Your Story}

The Harvard community has made this article openly available.

Please share how this access benefits you. Submit a story.

\section{Accessibility}


Research Publication No. 2015-3

February 17, 2015

Youth and Online News:

Reflections and Perspectives

\author{
Edited by: \\ Sandra Cortesi \\ Urs Gasser \\ With essays by: \\ Sarah Genner \\ Erhardt Graeff \\ Paulina Haduong \\ Rey Junco \\ Luis Felipe R. Murillo \\ Dalia Othman \\ Geanne Perlman Rosenberg \\ Emily Robinson \\ Mayte Schomburg \\ Brittany Seymour \\ Hasit Shah \\ Sara M. Watson
}

This paper can be downloaded without charge at:

The Berkman Center for Internet \& Society, Youth and Media: http://youthandmedia.org/publications/

The Social Science Research Network Electronic Paper Collection:

Available at SSRN: http://ssrn.com/abstract=2566446 
(1)(-)

Youth and Media

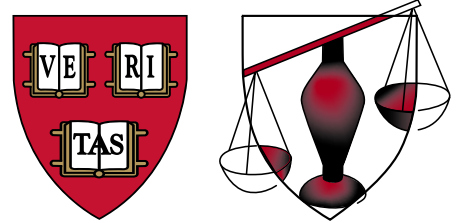

Berkman

The Berkman Center for Internet \& Society at Harvard University

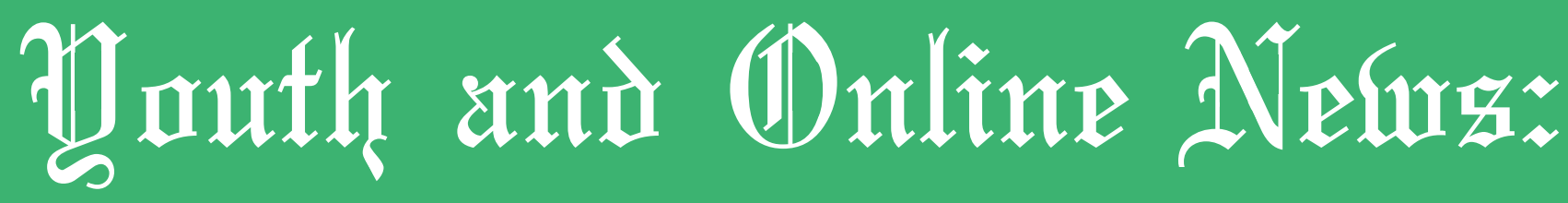

Reflections and Perspectives

\section{Edited by Sandra Gortesi 8 Urs Gasser}

With essays by Sarah Genner, Erhardt Graeff, Paulina Haduong, Rey Junco, Luis Felipe R. Murillo, Dalia Othman, Geanne Perlman Rosenberg, Emily Robinson, Mayte Schomburg, Brittany Seymour, Hasit Shah, and Sara M. Watson.

Illustrations by Elsa Brown

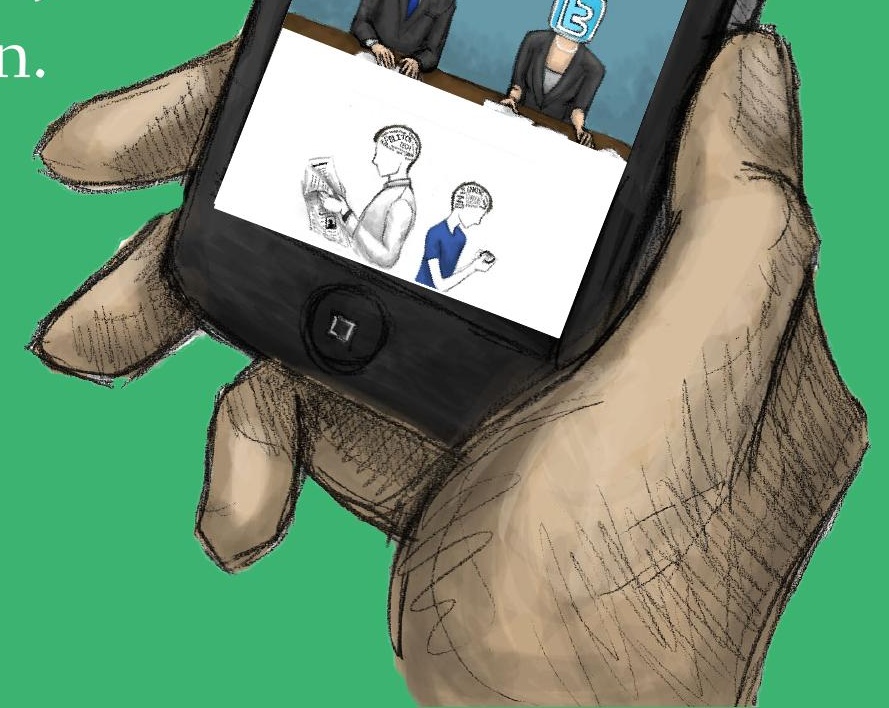


Published

February 20 I 5

Berkman Center for Internet \& Society

23 Everett Street, 2nd Floor, Cambridge, MA 02 I 38

+I (6 I 7 ) 495- 7547 (Phone)

+I (6 I 7) 495 - 764 I (Fax)

E-mail: youthandmedia@cyber.law.harvard.edu

Website: www.youthandmedia.org 


\section{About this Publication}

Over the past few years, the Youth and Media team has conducted extensive research aimed at better understanding how young people think about news, what their news habits and preferred news sources are, how they create, share, and otherwise interact with news, and what emerging news genres are - such as memes (for an overview, see http://youthandmedia.org/research-briefs/).

In parallel, the Youth and Media team served as the research, learning, and development partner to the Chicago-based core group of McCormick Journalism Program grantees ("Why New Matters" grantees) and the McCormick Journalism Program team. The collaboration between the Berkman Center and the McCormick Foundation was aimed at supporting the foundation's youth-oriented audience and general content initiatives in Chicago, as well as the "Why News Matters" program in particular.

This publication includes a series of short essays that offer interesting, alternative, exciting, sobering, unusual, out-of-the box perspectives, observations, or reflections at the intersection of news, digital media, and youth - broadly defined.

The contributions in this publication reflect the diversity of ideas and perspectives that form the core and spirit of the Berkman community. Some of the essays are closely connected to specific research and publications conducted by the Youth and Media team, others reflect more generally on personal observations and/or opinions, or highlight and discuss insights and learnings from other studies or concrete projects.

By making these essays available to the WNM community as well as the public at large, we hope to continue and further stimulate the conversation about both the challenges and opportunities children and youth encounter in the digital environment related to "news".

\section{Acknowledgments}

The editors wish to thank Oset Babur, Erin Maher, and Paulina Haduong for their editorial support and assistance, as well as Elsa Brown for her wonderful illustrations throughout this publication.

This work has been made possible by a Why News Matters grant from the Robert R. McCormick Foundation. Special thanks are due to Mark Hallett for his vision, support, and collaboration. 


\section{Table of Gontents}

How We Gommunicate. Paulina Haduong...................................................... 6 Gone are the days of sharing news stories and snippets with our friends via clunky emails, or even wordof-mouth. Mobile tools allow us to keep the information flow open and dynamic, through the use of readers and chat clients. Most importantly, the tools, hashtags, and captions we attach to news we share can help define their trajectories among our friend circles.

Of Newsfeeds And Timelines. Sarah Genner.................................................. 10 The digital generation is redefining the customary perceptions of news. For these young people, mobile apps and social media tools are a constant way to stay abreast of what's relevant to them; this includes everything from selfies to Buzzfeed listicles. In order for us to help today's youth become informed participants in the democratic system, we need to help them get access to stories about current events. Teaching youth about the relevance of a free press is as important as teaching them about newsfeed algorithms.

“But Ferguson was trending in my feed". Sara M. Watson........................... 14 If we better understand the rules of the algorithmic game, we have a better shot at helping youth understand how it impacts their unique experiences on the Internet. Developing digital literacies is critical for a generation that grew up with platforms like Facebook and Twitter. The more today's youth understand that algorithms have a real impact on their individual newsfeeds, the better they can contextualize their experiences in the World Wide Web of news.

Social Media: The Underdog of the News World. Hasit Shah......................... 17 Young people are turning to alternative sources to get their news. Providers need to cater to these audiences through their mediums of choice, which increasingly take the form of social media networks. News sources also need to be cognizant of how messaging clients are preferred ways for youth to share news snippets with one another, and work to tailor content to these uses.

Storytelling in the Age of News and Engagement. Dalia Othman.................. 19 Finding a harmony between typical youth lifestyles and traditional news mediums is becoming increasingly difficult, but it is also very salient given that these young people are the future audiences of news. Projects like NetStories work to address the gaps between interactive reporting and younger audiences by running storythons that help newsrooms cater to youth. The ultimate hope is that new methods of digital storytelling will find homes on our newsfeeds and our mobile screens.

News, Memes, and Givic Identity. Erhardt Graeff............................................. 21 Creative ways to bring people together in new communities on the Internet are all around us. In politics, media, and humanitarian campaigns, we are seeing a proliferation of users relying on tools like memes to voice their solidarity with various causes. Our civic identity is increasingly shaped by our social media use, where we navigate a sea of content to pursue new forms of political engagement. 
Web 2.0, Generation Z, and Health. Brittany Seymour \& Emily Robinson...... 24 Today's youth, termed Generation Z, are using the web to get answers to important questions. Our job is to make sure they avoid corrupt sites by making the accurate ones as user-friendly as possible. Health knowledge is an especially salient part of Generation Z's relationship with the Internet, and the information sharing that takes place on social networks as well as health forums are important mediums for them to engage with other patients and answer-seekers to form a unique camaraderie.

Social Media: The Unfair Victim of Misleading Media Reports. Rey Junco..... 27 Many educators are banning social media use in schools for fear that it serves as a distraction, and promotes narcissism at a young age. However, this attitude ignores the many benefits of social media use, chiefly as a way for young people to engage with content on the web, and share it with their peers. Youth norms for engaging with the news should be different than those we expect from adults. Therefore, it is important to reconsider the ways in which the Facebook newsfeed and Twitter streams have an advantage of relevance for the new generation, as opposed traditional media sources.

\section{From Terrifying Turkeys To Flying Penguins: Empowering Students To Be Better Informed. Geanne Perlman Rosenberg............................................. 29} The challenge for young people and students to be empowered as informed consumers and publishers of information is an uphill battle. They must learn to search for and evaluate the quality of information they access online and to be discerning in their information sharing and publishing activities and use of social media. If students learn to subject information to vetting processes and critical evaluation and verification, they can help ensure the dissemination of facts vs. myth and propaganda and misinformation among their peers.

\section{Independent Journalism as Transformative Experience. Luis Felipe}

R. Murillo.

Thanks to technological advances, almost everyone has the power to create content in the media stream. Handheld devices are a key way through which public participation in the news has skyrocketed, which helps the cause of news literacy amongst young people. The catch? Making sure every producer holds him or herself to a strict standard of journalistic integrity, so that the news they contribute is informative, accurate, and thought-provoking.

\section{Publixphere - A Political Platform for Young Gitizens. Mayte Schomburg..... 35}

Publixphere is a tool that enables young people to communicate about current events, and policy issues. The forum looks to bridge the gap between youth involvement and "established" politics, by emphasizing the importance of participation across a wide range of age groups. Furthermore, the site invites young people to set their own agenda for discourse, and serves as both an editorial and informational outlet. 


\section{How We Gommunicate}

\section{Paulina Haduong}

Berkman Center for Internet \& Society

http://fusion.net/story/31450/dark-
social-traffic-in-the-mobile-app-era

oh I read his newsletter

alex howard?

madrigal

madrigal thats right

he has a tinyletter

5 interesting things

science/tech

im sending you the howard one on pocket

|Text Message

A recent exchange via GChat.

From the moment I wake up until the moment I sleep, I'm talking to some of my closest friends, several of whom I rarely see. One-on-one and sometimes in groups, via iMessage, GChat, and text message, we send snippets of thought about anything and everything: what we're eating right now, what we're doing at work, something funny that happened on the bus, or YouTube videos we just found. I have no idea if this is weird or unusual behavior (full disclosure: I am a 23-year-old female working at the Berkman Center for Internet \& Society, so my circles might be more tech-savvy than most), but we've been doing it for years, preferring to livestream passing observations instead of writing long emails or scheduling Skype sessions in advance. This is as close to telepathy as we can get. 


\section{If you have time}

\section{Colin Hart}

$9 / 19 / 13$

to me ro

\section{This article is excellent}

\section{http://thenewinquiry.com/essays/whats-the-matter-with-the-modern-world-ionathan-franzen/}

A typical email from last year.

Ongoing conversations with friends have been like this for years, and with the increasingly seamless integration of apps across mobile devices and personal computers, the same conversation often jumps from medium to medium, or, from Facebook message to GChat to iMessage. As of one year ago, these streams of conversation often included emails, and my inbox was filled with emails from friends like this one - short, cryptic subject lines, sent at all hours, the message only a link and a few words of note. These emails are evidence trails, records of where we went and what we clicked. News stories we read, recipes we thought about making, mashups we listened to (note: In this case, I am defining news broadly; for further explanation, please refer to our recent paper "Youth News Perceptions and Behaviors Online: How Youth Access and Share Information in a Chicago Community Affected by Gang Violence" I).

That mode of communication is now gone, wiped out by other ways to share news articles and other items of interest across the Internet. Even though my research often touches on how young people use social media, the reality is that although I might use these semi-public spaces as news sources, my social networks are elsewhere, loosely connected by texts, instant messages, and "read later" apps such as Pocket or Instapaper. In other words, we drive web traffic amongst ourselves in ways that contribute to the dark social underbelly of the web. From the semi-public surface of social media, it appears as if we read very little and, indeed, hardly communicate online, but in the depths there are constant streams of communication.

For some of these chat apps, however, dark social has become increasingly trackable and demystified. In some contexts, for example, a remarkable amount of web traffic is being driven through WhatsApp (an app strictly for use on mobile devices), and while news sites often provide readers with several options for sharing on social networks (most often, Facebook and Twitter), a few are now providing a WhatsApp button as well.

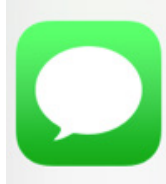

Message

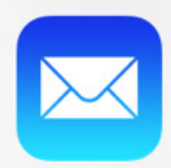

Mail

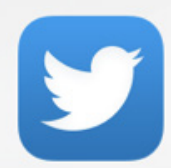

Twitter

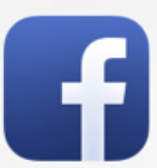

Facebook

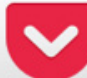

Pocket

My options for sharing via my iPhone 
I confess to not being a WhatsApp user, but I do use iMessage and Pocket in similar ways, as opposed to Twitter or Facebook. The recent and horrific events relating to Ferguson and Eric Garner, which have generated millions of social media interactions, have made it apparent that links posted to Facebook, at least within my friend network, are not links about communication, but about identity. Shared links and hashtags (\#blacklivesmatter) reflect not what we're reading, but what we want other people to know we're reading. These are links sent from one-to-many, instead of one-to-one. "This is where I stand," those links and statements into the void seem to say. "This is how I feel and this is who I am."

The links I used to send through email can now be sent directly through iMessage or Pocket/Instapaper, though there's a marked difference in the kinds of links sent through each. News sent through iMessage is often a quick read, meaning breaking, funny or important. I read the link, and immediately it is passed on to a friend. On the other hand, Pocket, Instapaper, and other similar apps store longform articles (which, despite the public conversation about technology and our short attention spans, continue to be widely read and shared) and other media, helping these tools act as both a reader and a repository for content. Here, the chain from me to a friend is slower and more thoughtful - one day, I might save something to Pocket, but it might take a few days before I read it, and it's only then that it might be shared with someone else. Anecdotal evidence from friends suggests that their behavior is similar - shortform media is shared via text/instant message, and it's shared at the moment of discovery, but longform is more often sent via these "read later" apps, and the time from a user's discovery to sharing with a friend is longer.

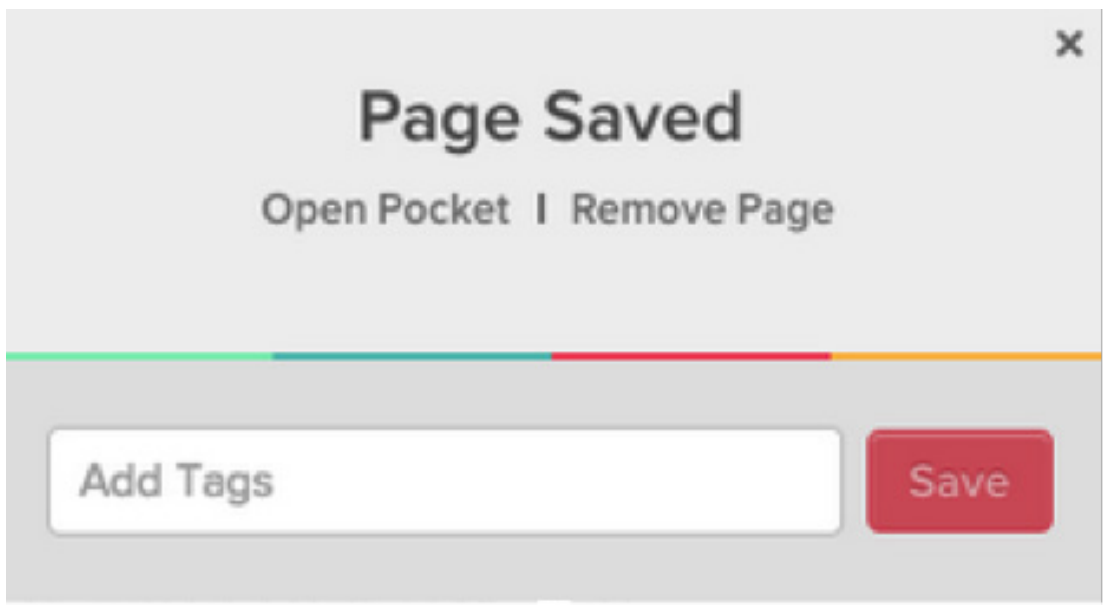

Saving longform articles via Pocket 
While past research has been focused on how we share news via Facebook, Twitter, and other social media, perhaps it is time that we turn to examining the "dark social" phenomenon more closely, both with quantitative and qualitative data (due to the nature of the phenomenon, qualitative data might be easier to gather). How are we sharing information online when it's not via social media, and why? Who are we sharing with? How can we promote more of this exchange and preserve records of how we traverse the web?

In short, there is clearly more work to be done. In the meantime, I'll stick to one more news source in my inbox: the email newsletter.

\section{References / Resources / Links}

I Cortesi, S., Haduong, P., Gasser, U., \& Beaton, M. (20 I 3, October I 8). Youth news perceptions and behaviors online: How youth access and share information in a Chicago community affected by gang violence. Berkman Center Research Publication No. 20 I 3- I 9. http://papers.ssrn.com/ sol3/papers.cfm?abstract_id=2342308 


\section{Of Newsfeeds and Timelines}

\section{Sarah Genner \\ Zurich University of Applied Sciences \\ Berkman Center for Internet \& Society}

Modern media junkies are glued to their smartphones looking at selfies on Instagram, their timeline on Twitter, and their Facebook newsfeed. We want to be fed constantly with live news and infotainment. Sometimes, we refresh our newsfeeds and timelines like trained monkeys and complain afterwards that we suffer from information overload. We are fed with unhealthy fast-food news, and digital natives in particular lack appreciation for high-quality journalism that costs both time and money. This is why the newspaper industry and traditional journalism are going down - and so is democracy, because of the filter bubble ${ }^{\mathrm{I}}$. Neil Postman was right after all, when he said we were amusing ourselves to death ${ }^{2}$. Just look at all those silly listicles and cat videos online!

But, wait. This is not the apocalypse. We are experiencing a major shift in how we use media. And with every historical change in media and communication technologies, there are pessimists and there are evangelists. Let's have a closer look.

No doubt, digital technologies are profoundly changing journalism and the way news is consumed. There are a lot of questions: What does 'news' mean to a generation that grew up with the possibility of everyone with Internet access being a creator of news? What do today's youth prefer to use as a channel to get the news they need in order to become responsible citizens and voters? Are digital natives ever going to pay for a newspaper subscription on- or offline? Do those who have grown up being able to access any website still care about news company brands? How do traditional news companies need to change their business model in order to win digital natives over?

Research from $2014^{3}$ shows that in case of inconsistent news reporting, teens trust traditional newspapers by far the most, outranking the TV, radio and online resources. But because of convergence - the possibility for media organizations or individuals to deliver or use text, audio, and video material on a single device - research on media use has become far more complicated. TV is online, radio is online, newspapers are online, citizen journalism is online, and so are many other news sources. Traditional news companies that used to publish print journalism or broadcast TV are now additionally online content providers who interact with users on social media. Surveys on media use and content creation by users have become incredibly complicated.

Facebook's newsfeed has turned into an important gateway to news in traditional online media. Twitter seems an important tool for journalists, but much less useful for distributing press articles to a broad audience, and even less applicable to a younger audience. Social media and their newsfeeds change the notion of news. Little is known about what "news" actually means to the digital generation. In their newsfeeds, they find their friends' news about where they spend their vacation, selfies with new outfits, as well as traditional news stories, and hopefully their friends' likes and comments. Yes, a lot of this content is not highly relevant from a traditional news perspective. But it might be for them. Some act as if 
before the Internet, there was only "hard news"; news of widespread importance, concerning politics, foreign affairs, or the like. But "soft news" is not an invention of the Internet: human-interest stories, entertainment, gossip have existed for many decades. Hard news is indeed important for future voters to make smart decisions, and for democracy in general. Traditional news media in Western democracies are indeed struggling to find their way in a new era. In the digital age, print is not dead and paywalls online are still complicated. Convergent newsrooms tend to fail as more web-only competitors arise, and listicles on Buzzfeed and HuffPo get more clicks than expensive "high-quality" journalism. There are quite a few challenges.

\section{Smartphones in most teenagers' pockets}

The recent boom of smartphones in particular is changing the way we create, consume, share, and interact online. The good news is that a growing number of teens read newspapers online (30\% in $20 \mathrm{I} 4$, $26 \%$ in 201 2) as our most recent representative Swiss "JAMES survey" shows. 4 Reading newspapers online has even become one of teens' favorite leisure activities. The majority of young people own a smartphone (in Switzerland, 95\% of $\mathrm{I} 2$ to $\mathrm{I} 9$ year olds in $20 \mathrm{I} 4^{5}$, in the U.S. and other countries, the numbers are rising constantly ${ }^{6}$ ). It is historical that almost everyone carries a device in their pocket at all times that allows them to stay informed at any time, anywhere. Swiss teens favor WhatsApp, Facebook and YouTube, followed by a news app. 7 Youth are news creators. Only a small percentage have their own blogs, or actually create relevant content online, but a larger number of youth share content, comment, and interact ${ }^{8}$. This not only involves cat videos, but also political memes that get created and shared on Facebook, Twitter, and Instagram about election campaigns, gun control, and civil rights.

Digital natives are used to being able to access news at any time. Still, a recent Swiss survey shows that social media is generally overrated when it comes to keeping this generation abreast of current national or global events. In Switzerland, the most popular news source for I 5 to 25 year olds are free print newspapers that flood Swiss public transport. The second most popular source for current events is the television, followed by online radio news sites, news apps, print papers and, finally, social media. 9

\section{Challenge for news organizations to help youth contextualize news stories}

The way youth actually use media is strongly influenced by their parents and what value they place in news. This is not specific to the digital age. Some teenagers are a lot more into hard news than others. Some prefer news on TV, others like traditional newspapers. Some are very savvy, in looking up several news sources online to verify the sources, and others are interested in viewing selfies and reading fashion news only. These are some major differences within the web generation that have often been overlooked.

Youth often complain that they lack time to stay informed about current events, and many experience information and news as an infinite ocean in which they float without any orientation. Young people usually lack contextual knowledge to be able to make sense of what is in the news. It remains a major challenge for news organizations to help the younger generation contextualize news stories.

Criticizing algorithms for their invisible decisions that decide what is newsworthy in our newsfeeds is all the rage among intellectuals. Media education in schools in recent years has focused a lot on potential dangers online, like uploading party pictures, privacy issues, or copyright infringement. Learning about algorithms could be a way to start educating youth on what is "relevant" news to them personally, to the town, city, or country or city they live in, and to the world. It is a way to start discussing Mark Zucker- 
berg's quote,

"A squirrel dying in front of your house may be more relevant to your interests right now than people dying in Africa."

Teaching youth about historical context and freedom of the press

But preparing youth for the relevant news in the digital age is about so much more than learning how algorithms work and how they filter newsfeeds. Knowing about global history and journalism is more important for youth than ever before, so they can understand what is relevant news, and what incentives journalists have when they pursue news stories. To know about media manipulation before the digital age will better explain why and how authoritarian regimes control and censor media and the web. Lessons from the past are important to make young people appreciate both freedom of the press, and high quality information. The debate about tabloid versus quality journalism and the role of advertising dates back much farther than just the digital age.

The challenge for news media organizations remains to deliver quality journalism and accept that both the Internet and mobile devices are here to stay. If they want to keep young readers and users, they need to make some changes. This includes working with news researchers to incorporate the younger generation's media habits with their idea of relevant accessible news stories. Perhaps we can start by providing our schools with ready-made materials on why news matters.

\section{References / Resources / Links}

I Pariser, E. (20 I 2, March 26). Filter bubbles, meet upworthy. http://www.thefilterbubble.com/. See also: Morozov, E. (20 I I, June i o). Your own facts. http://www.nytimes.com/20 i I/o6/ i $2 /$ books/review/book-review-the-filter-bubble-by-eli-pariser.html?pagewanted=all\&_r=o

2 Postman, N. ( 1 985). Amusing Ourselves to Death: Public Discourse in the Age of Show Business. Penguin Books.

3 Feierabend, S., Plankenhorn, T., Rathgeb, T. (20 I 4). JIM 20 I 4. Jugend, Information, (Multi-) Media Basisstudie zum Medienumgang I 2- bis i9-Jähriger in Deutschland. Medienpädagogischer Forschungsverbund Südwest. http://www.mpfs.de/index.php?id=2 76

4 Willemse, I., Waller, G., Süss, D., Genner, S., \& Huber, A.-L. (20 I 4). JAMES - Jugend, Aktivitäten, Medien - Erhebung Schweiz. Zürcher Hochschule für Angewandte Wissenschaften, Zürich. http://psychologie.zhaw.ch/JAMES

5 Willemse, I., Waller, G., Genner, S., Suter L., Oppliger S., Huber, A.-L.\& Süss, D. (20 I 4). JAMES - Jugend, Aktivitäten, Medien - Erhebung Schweiz. Zürcher Hochschule für Angewandte Wissenschaften, Zürich. http://psychologie.zhaw.ch/JAMES.

6 Madden, M., Lenhart, A., Duggan, M., Cortesi, S., Gasser, U. (20 I 3). Teens, and Technology 20 I 3. PEW Research Center and Harvard Berkman Center for Internet and Society. http:// www.pewinternet.org/20 I 3/०3/ I 3/teens-and-technology-20 I 3/

7 Willemse, I., Waller, G., Genner, S., Suter L., Oppliger S., Huber, A.-L.\& Süss, D. (20 I 4). JAMES - Jugend, Aktivitäten, Medien - Erhebung Schweiz. Zürcher Hochschule für Angewandte Wissenschaften, Zürich. http://psychologie.zhaw.ch/JAMES. 
8 Willemse, I., Waller, G., Genner, S., Suter L., Oppliger S., Huber, A.-L.\& Süss, D. (20 I 4). JAMES - Jugend, Aktivitäten, Medien - Erhebung Schweiz. Zürcher Hochschule für Angewandte Wissenschaften, Zürich. http://psychologie.zhaw.ch/JAMES.

9 Mediadaten 20 Minuten (20I3). Mediennutzung und -wahrnehmung bei Digital Natives. http://mediadaten.2omin.ch/wp-content/uploads/20 I 4/03/20-Minuten-Studie_Pendlerzeitungen_Informationsquelle_DigitalNatives.pdf

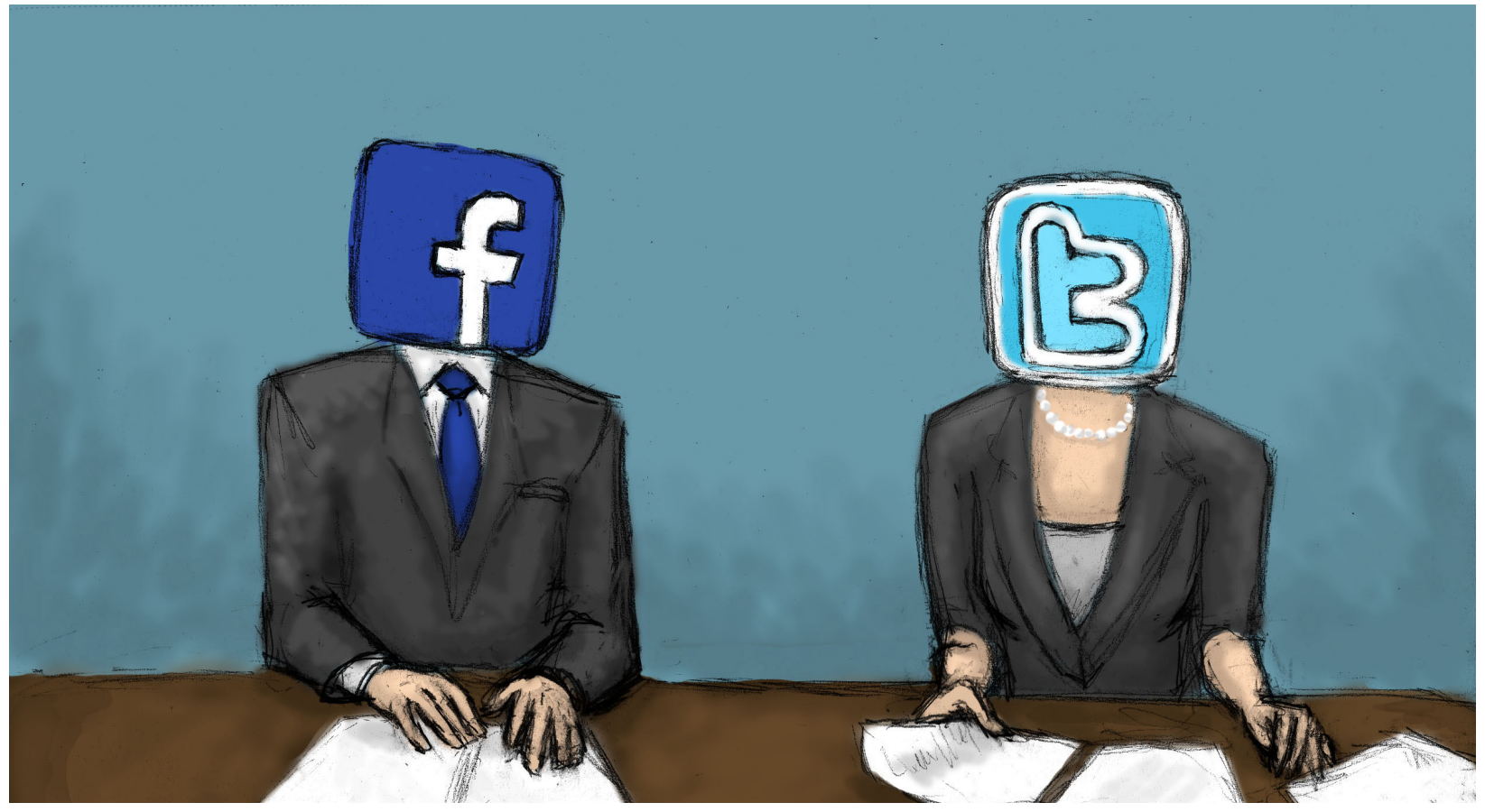




\section{"But Ferguson was Trending in my Feed"}

\section{Sara M. Watson \\ Berkman Genter for Internet \& Society}

I was at a journalism conference recently where the topic of algorithmic curation came up. One of the speakers cited the comparison between Ferguson trending on Twitter ${ }^{\mathrm{I}}$ while the Ice Bucket Challenge was all the rage on Facebook ${ }^{2}$. It was held up as an example of how platforms influence and shape news and shape sharing behaviors of their users.

One student in the audience raised her hand, piping up that she contested the premise that Ferguson hadn't trended on Facebook. "She was originally from St. Louis and all her friends from home had been talking about it, about race, about police violence, about protests. Ferguson was all over her Facebook newsfeed."

The discrepancy provided an illustrative moment. One the one hand, opinion and data had made claims about how algorithmic filtering practices of platform affect access to news on Facebook. "On the other hand", a personal experience of the same news event had differed drastically from the larger collective narrative about how news spreads online, and how politically sensitive topics are discussed within youth peer networks on Facebook.

That one student, away from home at school in Milwaukee, hadn't felt distant from the activities in Ferguson. She was deep in it in her feed. The news was blowing up within her situated sphere of influence. This is how she experienced Ferguson.

Still, she had a hard time conceiving how Ferguson hadn't made it into the feeds of others on Facebook. She contested the speaker's claim with her own, situated and personal experience of the algorithmic curation.

\section{Digital Literacy in Context}

The greatest challenge we face in addressing the technical platforms that shape our information experiences is in demonstrating the effects between inputs and outputs in the system. Just as news literacy aims to develop skills to "understand a source's agendas, motivations and backgrounds," digital literacy needs to do the same of the platforms and their business models and motivations for providing value to consumers. We need tools that not only build diversity and solve for homophily problems, but also introduce us to the underlying editorial structures of these novel information platforms.

Digital news literacy ought to be taught by example and in context. Youth need to understand how algorithms affect their unique experience, not just how they influence everyone's experience abstractly and in principle. We need more tools that allow youth to interact with the algorithm and see the micro effects of subtle changes from various inputs, like who you follow, what posts you comment on or re-share, and what things you like and click through. 
Tools like Floodwatch's 3 ad tracking database allow us to compare our personal experience to that of others in a shared demographic profile. We could use still more technical interventions to help show variation in personalization.

What can youth learn about the way technical platforms work by comparing and contrasting the trending topics they see on Facebook and Twitter with peers in their network, and with others outside their network? What will they learn about what newsworthiness is in these personalized contexts?

If we take into account the personal, contextual experience of youth in teaching news literacy, we can help them to understand their place in a larger civic discourse around news and access to information by making it grounded, personal and real in the contexts where they get information today.

\section{Ethnography in Youth and Media Research}

News literacy goes beyond the sources that youth get information from, and how social media influences their filter bubble. It's also about developing algorithmic literacy, for understanding the curatorial and editorial role of the platforms they interact with in their media environments.

Ethnographic interview work has vastly expanded our understanding of youth media practices by meeting them where they are and elevating their voices and concerns. Youth news experiences are inherently personalized now, and research methods for understanding those technical experiences must be as well.

\section{Ethnography in Technology Journalism}

Ethnographic approaches to knowledge and experience of algorithms should also expand to the media outlets covering our evolving relationship to technology. Journalists can play a role in developing digital literacy for access to information for their audiences by paying attention to and covering grounded, individual interactions with these systems.

That has been my methodological approach to "Living with Data,"4 the series I developed for Al Jazeera America. In it I examine encounters that illustrate our personal, situated experience of these tools, following reader submissions about our expectations about how these systems work or should work, and what is actually technically happening. The series aims to teach critical digital literacy through examples.

In part, this series was designed to refute the common argument that "I have nothing to hide" or that privacy concerns are too abstract for people to understand their effects. My aim is to illustrate through real experiences how autonomy and privacy are influenced by these sociotechnical systems that govern our access to information. A mission to develop critical digital literacies becomes especially important for a generation that takes Facebook and other social media platforms for granted.

This grounded approach makes the harms, or the surprises of data more personal, and more relatable. So while your experience may be very different from mine, I can begin to understand the inner workings of these algorithmic curatorial decisions because I can grasp the effects at a personal scale. I can compare my experience of Ferguson on Facebook against everyone else's experience of the Ice Bucket Challenge.

Grounding coverage of these technical stories makes technical subjects more accessible, but also helps to make the individual stakes more present and clear. 


\section{References / Resources / Links}

I What Happens to \#Ferguson Affects Ferguson: Net Neutrality, Algorithmic Filtering and Ferguson. https://medium.com/message/ferguson-is-also-a-net-neutrality-issue-6 $\mathrm{d}_{2} \mathrm{f}_{3} \mathrm{db} 5 \mathrm{r}$ ebo

2 Ingram, M. (20 I 4, August I 8). Twitter vs. Facebook as a news source: Ferguson shows the downsides of an algorithmic filter. https://gigaom.com/20 I 4/08/ i 8/twitter-vs-facebook-as-a-newssource-ferguson-shows-the-downsides-of-an-algorithmic-filter/

3 Floodwatch. http://floodwatch.o-c-r.org/

4 Watson, S. M. (20 I 4, September 30). Living with Data. Tools that help us see the data behind the browser. http://america.aljazeera.com/articles/20 I 4/9/30/browser-tools.html

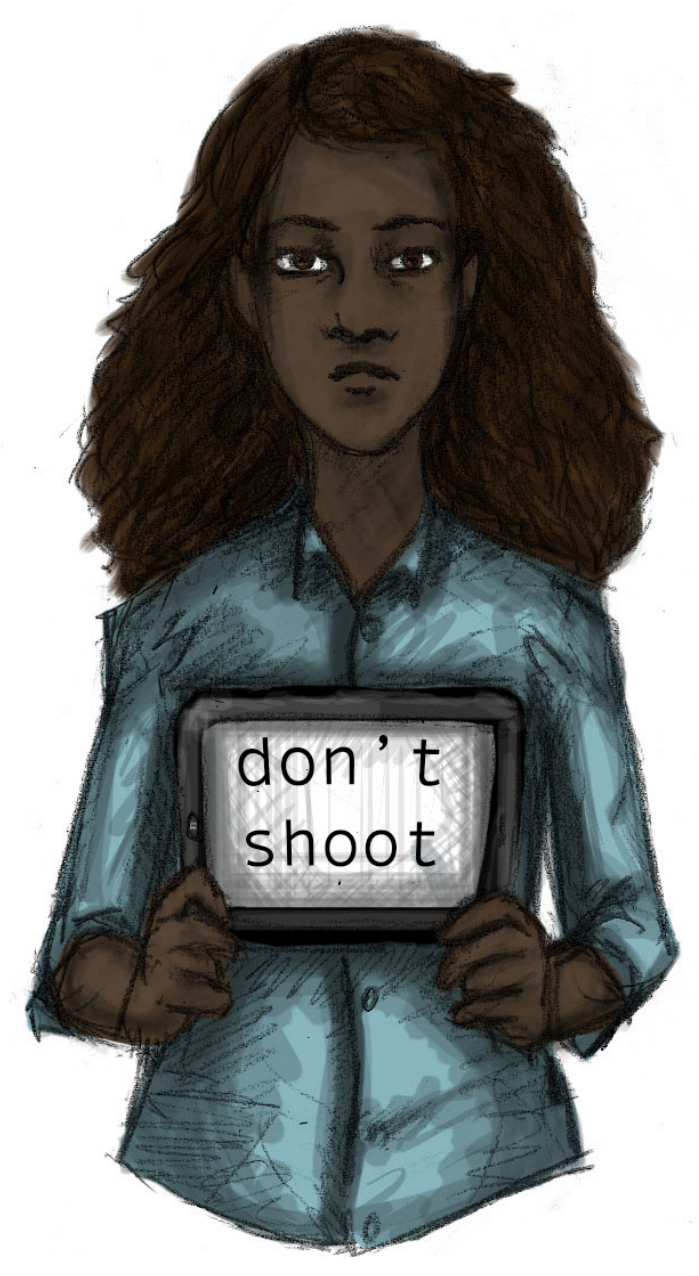




\section{Social Media: The Underdog of the News World}

\section{Hasit Shah \\ Berkman Genter for Internet \& Society Former BBC}

The BBC (British Broadcasting Corporation) has a responsibility to provide a news service to everyone in the United Kingdom. But if we now accept that young people might not tune in to the BBC's TV or radio channels, or might not even click on its news homepage, we have to find out how else we can reach them.

Newsbeat is a long running radio news service in the UK, aimed at people in their teens and early twenties. Although it still attracts a large radio audience, its new editor, Louisa Compton, is pressing ahead with digital plans because of the changing habits of young British people. "We know our audience is more excited by news and consumes more news than any other generation," she says.

"[But] now they live their life through their phones and news is constantly reaching them."

Facebook and Twitter are well-established and reliable platforms for media companies. We know how to use them well, and in return, we receive solid corporate support as well as the power to reach and interact with audiences so much better than ever before. The decisions made by the people who run these platforms, and arguably control the social web, have a major impact on how news is disseminated.

Recently, apps like Snapchat, Instagram and WhatsApp have emerged, bringing with them large, growing numbers of young users. Since the end of September, I have been running a project that aims to find out what BBC Radio - and its audience - can gain from using these platforms, particularly Snapchat.

If you are between the ages of $\mathrm{I} 5$ and 24 in the UK, there's a I in 3 chance that you spend a significant amount of time on your smart phone using Snapchat. It is a multimedia-messaging app that deletes content once it has been viewed. This appeals to the natural impatience and attitudes of teenagers precisely because, as the New York Times' Nick Bilton writes, it is

"fast, ugly and ephemeral". I

It is not surprising that many media companies and consumer brands, attracted by the size of the user base, have been experimenting with ways to use Snapchat to deliver content, connect with audiences, and promote their brands.

On the surface, it seems to make a great deal of sense to use as many channels as possible to deliver content. They are popular, available, and free to use. 
But despite the popularity of these apps there are many reasons to be cautious. For this project, my role is to balance the desire to innovate and connect with a pragmatic look at the costs and obstacles of using third-party platforms. There has to be a clear set of justifications for freely supplying BBC content which our audience has paid for - to a platform we don't own or control.

Twitter and Facebook supply detailed analytics. We can easily see how well a post has done, and the extent to which a post has helped amplify the success of a piece of content. The newer platforms, however, do not give us quite as much information, making them more difficult to justify without a metric of success.

Posts on Twitter and Facebook also send users back to the BBC's own platform. Snapchat and Instagram, however, do not allow us to post links. This creates a problem around exclusivity and access. The BBC aims to make digital content 'platform neutral'. If a user does not have a social media account, they should still be able to access a particular news story on the BBC's website. But technically, content on Snapchat and Instagram is only available to users of those platforms. While these applications are undoubtedly popular, they do not provide universal accessibility.

Creating tailored content for a platform that does not supply any detailed measure of success may not be the best use of finite production resources and limited time. That content must also be of the high quality expected from the BBC. Snapchat is deliberately "fast, ugly and ephemeral". That means it works well as a private messaging service between friends, but BBC journalism is not meant to look sloppy. BBC content should probably also end up as part of a wider digital archive.

There are numerous other issues to do with legal analysis of the terms and conditions of any platform that is not the BBC's own; of editorial compliance (all BBC journalism should have been checked by at least one other person before it is published/broadcast); fair trading, and so on.

The basic business case for this project is that the BBC must serve young users as well as it can. That audience is mostly digital. It is therefore most reasonable to attempt to use popular platforms to carry the BBC brand and its content.

But as we have seen, it is far from straightforward. There will be at least one trial, more research and eventually, a judgment call. For the moment, it is probably best to retain a degree of skepticism. Ultimately, the BBC wants to serve its audiences as well as possible, but it is not yet absolutely clear that some of these messaging apps give us the best way to do that.

\section{References / Resources / Links}

I Bilton, N (20 I 4, January 27). Why I use Snapchat: It's fast, ugly and ephemeral. The New York Times Bits. http://bits.blogs.nytimes.com/20 I 4/o I/27/why-i-use-snapchat-its-fast-ugly-andephemeral/ 


\section{Storytelling in the Age of News and Engage- ment}

\section{Dalia Othman \\ Berkman Center for Internet \& Society \\ Center for Givic Media, MIT Media Lab}

I grew up in a household that constantly watched the news. Even though my parents filtered what I watched, my interest in the news kept growing and I always found a way to access the news. Eventually, as a young teenager I was able to read and watch the news freely with the introduction of the Internet,. I spent a lot of my time on a variety of news sites, and I recall my frustrations at the time with how little I was allowed to engage online with the news reports. Things are different today, where technological development enables people to engage with the news in the form of comments, content creation, and more and more through interactive stories. These developments have led me to realize that there is great potential in digital storytelling. It can be deployed as a new form of audience engagement, especially amongst the youth. It is the reason behind my work on NetStories, a project started to promote digital storytelling amongst communities, classrooms, and newsrooms.

In the past decade or so, technological developments and social media have enabled people to engage with each other and with the content they read online. As a result of these developments, the role of the audience is amplified in the news making process. The New York Times Innovation Report ${ }^{\mathrm{I}}$ of 20 I 4 explored the research and discoveries made by the Times regarding capturing audiences. One of the key takeaways from the report worth noting here is the process of discovery and experimentation. This process focused on evergreen content and the ability to package and personalize the content in a way that engages the audiences through interactivity. Ultimately, the push towards interactive packaging is starting to change the nature of the news coverage, amounting to the rise in data journalism and interactive stories within many large media agencies such as the New York Times and The Guardian.

Moreover, we are looking at a highly connected audience, where over $37 \%$ of US youth are connected to the Internet through their smartphones and over $93 \%$ of them have access to a computer. ${ }^{2}$ These numbers are only going to increase, and newsrooms need to look at this connected generation as the new audience they need to draw in. Projects that focus on classrooms such as the Information Quality and News Literacy project established by the Youth and Media Project at the Berkman Center 3 can help promote a more news literate youth that is willing to engage with such content.

Literacy projects and the classrooms are where media organizations can push for the creation of more interactive stories as a way to engage their future audience. Incorporating stories and storytelling tools in these settings helps develop a more engaging approach. This is a goal that the NetStories project strives to achieve, namely by promoting a better understanding of these tools and their capabilities.

Emerging from a void in information about digital storytelling and trans-media tools, NetStories 4 aims to establish an innovative method in incorporating digital and interactive storytelling in newsrooms, class- 
rooms and community driven organizations. The project encompasses all of a resource site that would empower people to create stories by providing information about the storytelling tools available in the field. Within the educational mission of the project, the site also offers a review page that will be used by college classrooms. It is the goal of this page to encourage students studying new media and data storytelling to review the tools as a way to learn more about the capabilities of these tools. Accompanying the site is the NetStories card game that promotes strategically thinking of online stories while referring to the assortment of tools that are available. Furthermore, the project team is working on developing a curriculum module that would address the literature built around the field of storytelling, civic engagement and newsroom innovation. The educational content on the site will target classrooms and newsroom alike to help encourage digital and interactive storytelling.

In addition to the work being developed on the NetStories site and card game is the intention to run a number of storythons (story hack days) in the newsrooms and classrooms. These storythons aim to engage reporters and youth through the power of interactive stories and achieve an in-depth understanding of the tools available that can make these stories possible. By bringing people from newsrooms (especially small newsrooms that cater to specific communities) and facilitating their interaction with audiences in the classroom, the storythons will help newsrooms adopt content and stories that cater to the youth. The storythons will also help newsrooms to better understand the needs of the new audiences and what these audiences seek in both interactivity and content. While NetStories is a pilot project, the shift in the news industry towards a more interactive approach is proving that there is a vital need for newsrooms to adopt new methods towards digital storytelling, while keeping in mind the interests of the future consumers of news.

\section{References / Resources / Links}

I Abbruzzese, J. (20 I 4, May i 6). The Full New York Times Innovation Report. Mashable. http:// mashable.com/20 i 4/05/i 6/full-new-york-times-innovation-report/

2 Madden, M., Lenhart, A., Duggan, M., Cortesi, S., \& Gasser, U. (20 I 3, August I 5). Teens and technology. Pew Internet \& American Life Project. http://pewinternet.org/Reports/20I3/ Teens-and-Tech.aspx

3 Information Quality. Youth and Media. http://youthandmedia.org/projects/information-quality/

$4 \quad$ Netstories. http://www.netstories.org/ 


\section{News, Memes, and Givic Identity}

\section{Erhardt Graeff \\ Genter for Givic Media, MIT Media Lab \\ Berkman Center for Internet \& Society}

Measuring engagement with news is comprised of more than just a set of quantitative metrics. It is a process of civic identity construction that unfolds on social networks when someone decides to share a piece of content. This is a core part of contemporary civic learning and political participation.

In his book Post-Broadcast Democracy, Markus Prior uses the term "by-product learning" to refer to learning "politically relevant facts as a by-product of nonpolitical routines" $(2007,4)$. Prior derives this concept from his study of the "efficiency" of citizens' media environments, finding that less efficient systems like broadcast television actually produce high levels of by-product learning because exposure to political information was high when so few channels and programming options existed.

Ironically, in the age of "information overload" with a proliferation of free news online and readers spreading their attention across many sources, we have adopted new centralizing mediators in the form of social networks. One important example is Facebook, which services a broad array of information, entertainment, and social needs. Historically, one's choice of news source was an expression of identity through ideological affiliation, or professional membership. Now, rather than subscription and conspicuous print editions, we signal these things through the headlines we choose to share with our Facebook friends or Twitter followers.

Identity construction on social networks is a social process, whereby our identity is reflected and refracted in our engagement with others on the platform. We test our identity to see how peers respond, experimenting in ways that chart our connections to others. This represents identity and community construction, which is built on the personal and professional news and other information-bearing content we add to our social networks. As we see ourselves or ask others to see us through issues we share or current event-based jokes we make, we explore and negotiate our role in society as well as to what or to whom we feel responsible. This helps to construct our civic identity.

One way I have looked at this process is through the creation and sharing of "memes," particularly the election memes surrounding the 20 i 2 U.S. presidential election campaigns.

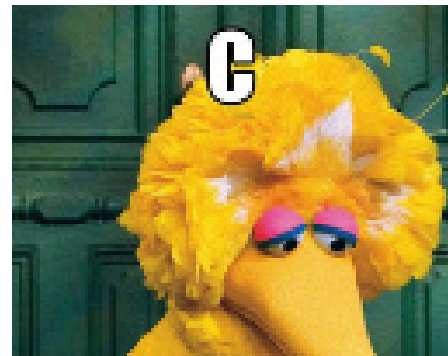

Fired Big Bird

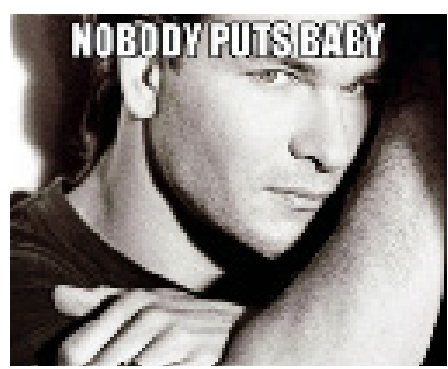

Binders Full of Women

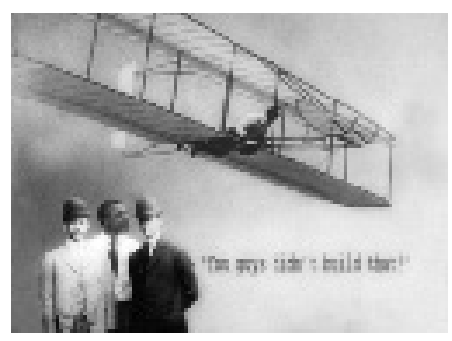

You Didn't Build That 
These "election memes," largely in the form of image macros, involved taking sound bites from the candidates' debates and speeches and turning them into "digital content units" of political satire "circulated, imitated, and/or transformed via the Internet by many users," to paraphrase Limor Schifman's definition of "internet meme" (2013, I 77).

The popularity of image macro memes like those seen during the 20 I 2 election derives in part from the relative ease of generating and sharing them. Image macro meme generator websites, like quickmeme. com, memegenerator.net, and imgflip.com, simplify the process of managing the process of uploading your image and overlaying the classic bold white font with your own words added through a text box. They also host galleries of all of the memes created using the same image, which may facilitate their sharing. The real power of this form of political participation is the ease of sharing.

Sharing or circulating a simple image macro via personal social networks, what Jenkins, Ford, and Green call "spreadable media" (20 I 3), represents a political speech act itself. In our "networked public sphere" (Benkler 2006), barriers to entry have been lowered, but so have the barriers to sharing, thanks to audiences on Twitter coalescing into publics around hashtags, on Tumblr through tagging and curation, and on Facebook through shared identity construction.

Looking at new social movement models like the Arab Spring, Occupy, and the Spanish indignados, Bennett and Segerberg (20 I 2) identified the power of meme sharing, calling it the "linchpin of connective action." They argue that sharing political memes can power "connective action networks" through personal expression over social networks, rather than top-down forms of collective action. In some cases these networks can be organizationally enabled through technological support and moderation to produce loosely coordinated, yet effective movements.

The propagation of these politicized cultural artifacts may seem trivial and guilty of "slacktivism", but the sharing does real political work in terms of creating a moment and a networked public with power greater than the sum of its parts. Friends or followers are exposed to the sharer's otherwise unspoken political opinions, and given the opportunity to participate by forwarding memes.

Memes can act as shibboleths - they indicate that you are part of the in-crowd, you get the joke, you were there when it happened. This feeling of inclusion can inspire further and future discourse. And it's not just political campaigns that have latched on to this creative energy and powerful form of identity and community construction. In March 20 I 3, Human Rights Campaign (HRC) rallied around two Supreme Court cases on gay marriage. They encouraged their Facebook followers to adopt HRC's red-tinted logo as a their profile images to demonstrate their support for marriage equality. Tens of thousands used and remixed the profile image, and the social media shares drove hundreds of thousands of visitors to the HRC website and the campaign's petition (HRC 20 I 3).

Of course, this type of connective action can silence others, such as those who do not agree with the stance taken by what appears to be a majority of their friends on Facebook; they feel unsafe in voicing their own dissent. It's not perfect recipe for productive discourse, but it may be one of the few avenues available when a voice is so marginalized that the only way to be heard is through shocking the broader culture into acknowledgment, as in the "impure dissent" embodied by hip hop culture (Shelby forthcoming). When we pay attention to that which shocks us, we achieve that bit of learning that collectively 
propels us in our understanding of the world. We are informed by our participation, and by what everyone else's participation produces. In this contemporary brand of news engagement, we co-construct the news ecosystem as we do our communities and our own identities.

[This essay is adapted from a forthcoming case study "Binders Full of Election Memes: Participatory Culture invades the 20 I 2 U.S. Election” in Civic Media Project, edited by Eric Gordon and Paul Mihailidis.]

\section{References / Resources / Links}

Benkler, Y. (2006). The wealth of networks: How social production transforms markets and freedom. New Haven: Yale University Press.

Bennett, W. L., \& Segerberg, A. (20 I 2). The logic of connective action. Information, Communication \& Society I 5 (5): 739-68.

Human Rights Campaign (20 I 3). The human rights campaign at the U.S. Supreme Court: A transformative moment for equality. http://hrcportlandgala.org/Forms/SupremeCourt_Accomplishments-FINAL.pdf.

Jenkins, H., Ford, S., \& Green, J. (20 I 3). Spreadable media: Creating value and meaning in a networked culture. New York: NYU Press.

Marwick, A. (20 I 3). Online Identity. In J. Hartley, J. Burgess, \& A. Bruns (Eds.), Companion to new media dynamics. Blackwell Companions to Cultural Studies (355-364). Malden, MA: Blackwell.

Prior, M. (2007). Post-Broadcast democracy: How media choice increases inequality in political involvement and polarizes elections. New York : Cambridge University Press.

Seitz-Wald, A. (20 I 2). Matt Ortega: The man behind Mitt Romney memes. Salon, March 23. Accessed June 7, 20I4. http://www.salon.com/20I2/03/23/matt_ortega_the_man_behind_ mitt_romney_memes/.

Shelby, T. (forthcoming). Impure dissent: Hip hop and the political ethics of marginalized black urban youth. In D. Allen \& J. Light (Eds.), From voice to influence: Understanding citizenship in a digital age.

Shifman, L. (20 I 3). Memes in digital culture. Cambridge, MA: MIT Press.

Shifman, L., Coleman, S., \& Ward, S. (2007). Only joking? Online humour in the 2005 UK General Election. Information, Communication \& Society, I $(4): 465-87$.

Stromer-Galley, J. (20 I 4). Presidential Campaigning in the Internet age. New York, NY: Oxford University Press.

Wallsten, K. (2० I o). Yes we can: How online viewership, blog discussion, campaign statements, and mainstream media coverage produced a viral video phenomenon. Journal of Information Technology \& Politics, 7, I 63-I 8 I . 


\section{Web 2.0, Generation Z, and Health}

\section{Brittany Seymour, DDS, MPH \\ Harvard School of Dental Medicine \\ Harvard Global Health Institute}

\section{Emily Robinson \\ Harvard Global Health Institute}

Our revolutionary digital environment has changed the way society consumes information, and new and emerging media technologies are empowering individuals in ways never before possible. Today, fringe political forces, Web based micro businesses, and ad hoc bloggers are highly influential societal entities, as described in Mele's The End of Big ${ }^{\mathrm{I}}$. What historically required robust physical infrastructure and resources now only requires a kitchen table and an Internet connection, or most dramatically just, a handheld device and mobile broadband. While Millennials, Gen X, and older generations have been affected by this change, perhaps no other demographic will be more influential in furthering our information transformation than Generation Z: today's youth. Generation Z will feasibly be responsible for a total paradigm shift in information production and consumption, a "media mutiny." Research from the Joan Ganz Cooney Center ${ }^{2}$ has found that children as young as eight years old engage socially to interact online, best defined not by the type of platform they are participating in, which is a restrictive metric for youth, but by their activities and digital behavior. Indeed, recent research from the Berkman Center for Internet and Society 3 supports that youth are contributing to structural shifts in how information and knowledge are created, shared, and recreated. 4

Emerging digital trends and Web 2.0 practices, as described by Cortesi and Gasser5, include both new forms of engagement with information online as well as new types of gatekeepers. As they collide with the vast digital knowledge climate, youth demonstrate a high affinity for active participation, iteration, and creation as opposed to simply consuming material online. One could argue that these behaviors are more than mere trends, but instead represent a new culture of knowledge creation and dissemination. In response, budding 2 ist century citizens must possess astute digital literacy, a skill that cannot passively be acquired, but must be taught - a paradox for an age group comprised of "digital natives." 6 For example, a recent study of upper and lower middle-income youth found that youth do a poor job of locating, evaluating, synthesizing, and communicating information online. Even more striking was the disparity between the two groups, with the bottom tier of middle-income students demonstrating to be almost a full year's worth of learning behind compared to their upper middle-income peers. 7 The National Council of Teachers of English standards are urging for improved digital literacy to empower students as both consumers and producers 8 who will make informed judgments about the quality and accuracy of online information. This becomes essential to engage with complex scientific and health information, especially to avoid exacerbating existing health disparities. Too often, lay digital contributors are unable to demonstrate adequate abilities for accurate analysis, synthesis and evaluation of the subtle yet significant complexities embedded in scientific information. This leads to a highly confusing environment for health information online. 
Health experts have witnessed a downside to this new digital knowledge culture, as played out by Gen X and Millennials, through a case study of childhood vaccines. The Pew Internet and American Life Project found that 8 out of $\circ$ adult Internet users search for health information online, including on social media platforms. 9 It has also been documented ${ }^{\mathrm{I}}{ }^{\circ}$ that social platform networks have influenced popular opinion towards vaccinations. I I With such a large volume of social information contributors and the diversity in contributor skillsets, the Web 2.0 age of health information has in fact become a digital pandemic of misguided and incomplete scientific misrepresentation. This dangerously impacts attitudes and perceptions about the safety and efficacy of vaccines. Our own research (forthcoming in the May issue of the American Journal of Public Health) found that social diffusion of a scientific publication mimics a game of telephone, with inaccuracies mounting as information gets further from its origin. Consequently, despite the fact that the 20 th century alone experienced the largest gain in life expectancy in global history, and it is possible to largely attribute this change to childhood vaccinations, we have in recently seen the marked return of preventable childhood diseases in record numbers due to deliberate vaccination opt-outs by parents. The novelty and empowering nature of co-created contribution to a "fingertip accessible" but corrupt information ${ }^{\mathrm{I} 2}$ environment has perhaps created a precariously autonomous and entitled approach for health information seeking and corresponding behaviors. But what happens when this new digital knowledge culture is no longer novel, as is the case with Generation Z, digital natives highly accustomed to the interactive and iterative culture of Web 2.0? Will they see through the novelty and be more capable of scrutiny, recognizing that advocacy does not always represent accuracy?

We are now encountering a health-specific "digital divide." On one end of the information transition spectrum, health experts and scientists ${ }^{\mathrm{I}} 3$ are still narrowly focused on the hierarchical broadcast distribution of static content designed for consumption. On the other end, youth are active engagers, producers, and creators of knowledge through iterative social diffusion of content. By engaging with youth as partners in our mission to improve online health literacy, and linking this relationship to health information, we have an opportunity to bridge both the online and health-specific "digital divides." Indeed, when Dr. Michael Rich, Director of the Center on Media and Child Health ${ }^{\mathrm{I}} 4$ at Boston Children's Hospital, provided cameras to young people with chronic medical conditions to document their experiences and needs, these young people received better care and had better clinical outcomes ${ }^{\mathrm{I}} 5$. The use of audiovisual media forged a crucial partnership. Physicians were granted a privileged view into the context in which their young patients lived, and the young people were able to both actively participate in and have control over how they shared information about their own health and well being. 6

What can we learn from these cases about information sharing, the influence of online social networks, improved health communication, and ultimately, changes in behavior with regards to how youth engage online? We have an opportunity to close the gap and learn about the ways to apply digital platforms to promote positive health decision-making with Generation Z. We can embrace a new culture of knowledge creation and dissemination for optimal health behaviors and outcomes by promoting proper education and attention to online literacy. This requires empirical strategies, new research, and increased attention from health experts to engage and empower youth. 


\section{References / Resources / Links}

I The End of Big: How the Digital Revolution Makes David the New Goliath. http://endofbig. com

2 Grimes, S., \& Fields, D. (20 I 2). Kids Online: A new research agenda for understanding social networking forums. http://www.joanganzcooneycenter.org/publication/kids-online-a-new-research-agenda-for-understanding-social-networking-forums/

3 Berkman Center for Internet \& Society. http://cyber.law.harvard.edu/

4 Gasser, U., Cortesi, S., Malik, M., \& Lee, A. (20 I 2). Youth and digital media: From credibility to information quality. Berkman Center for Internet \& Society. http://ssrn.com/abstract=2005272

5 Cortesi, S., \& Gasser, U. (forthcoming). Youth online and news: A phenomenological view on diversity. International Journal of Communication.

6 Prensky, M. (200 I). Digiral Natives, Digital Immigrants. On the Horizon (MCB University Press).

7 Havlik, B. (20 I 4, August 27). How social media can support science and digital literacy. Engaging Science. http://www.pbs.org/wgbh/nova/blogs/education/20 I 4/o8/how-social-media-can-support-science-and-digital-literacy/

8 National Council of Teachers of English Framework for 2 ist Century Curriculum and Assessment. Positions and Guildelines. Adopted by the NCTE Executive Committee November I 9, 2008. Updated February 20 I 3. http://www.ncte.org/library/NCTEFiles/Resources/Positions/Framework_2 IstCent_Curr_Assessment.pdf

9 Fox, S., \& Jones, S. (2009, June). The social life of health information. Pew Internet. http://www. pewinternet.org/20 I I/05/ i 2/the-social-life-of-health-information-20 I I /

Centola D. (20 I 3). Social media and the science of health behavior. American Heart Association. Circulation 20 I 3; I 2 7:2 I 35-44. http://circ.ahajournals.org/content/ I 2 7/2 I / 2 I 35

Salathé M., \& Khandelwal S. (20 I I). Assessing vaccination sentiments with online social media: Implications for infectious disease dynamics and control. PLoS Comput Biol, 7( I ०): e I 002 I 99. doi: I ०. I 37 I/journal.pcbi. I ००2. http://www.ncbi.nlm.nih.gov/pmc/articles/PMC 3 I 928 I $3 /$

Informing the news: The need for knowledge-based journalism. http://journalistsresource.org/ informing-the-news\#

I 3 Journalism and social media as means of observing the contexts of science. (n.d.). BioScience, 284-287.

I 4 Center on Media and Child Health. http://cmch.tv/

I 5 Rich, M. (2004). Health literacy via media: Video intervention/prevention assessment. http:// abs.sagepub.com/content/48/2/ i 65.short

I6 Rich, M. (2004). Health literacy via media: Video intervention/prevention assessment. http:// abs.sagepub.com/content/48/2/ i 65.short 


\section{Social Media: The Unfair Victim of Misleading Media Reports}

\section{Rey Junco \\ lowa State University \\ Berkman Genter for Internet \& Society}

A few years ago I published a research paper on how Facebook use led to improved student engagement. I One of the findings was that students who spent more time on Facebook also spent more time participating in offline campus activities. This finding, of course, was contrary to the popular notion that "social media is keeping youth from interacting offline." Student-run newspapers were very interested in doing stories on my findings and I was contacted by a large number of student reporters. What was most interesting was that just about every reporter relayed a form of this same story:

"I was talking to my friends about your findings and they were surprised that there are actually benefits to Facebook use."

I started asking these student reporters more about this - in essence, I was collecting more data to contextualize my findings. They shared that "they have been told" that social media are bad for them and that these technologies detract from the face-to-face interactions that these students have.

This was no surprise - teachers and parents tend to have a negative view of social media. Social media are banned in almost all primary and secondary schools with the implied belief that these technologies have no educational value. Popular media promote the notion of how social technologies are "ruining our children." Some example headlines include "Is Facebook leading to narcissist outlook?" "Anxiety and alcohol use linked to Facebook" and "Facebook use can lower grades by 20 percent." But it's not just the headlines - these sentiments are woven through most news articles about Facebook and spoken as truths in casual conversation. Often when I tell people that I research how youth use social media like Facebook, they respond with a version of "Yeah, it's terrible isn't it? They don't know how to interact with one another anymore." People believe this because it has an element of what Stephen Colbert called truthiness - that something is true because in one's gut, they believe it to be so.

The truthiness of these beliefs about youth social technology use is fueled by alarmist stories in the popular media. What's odd about these beliefs is that they contradict what is shown by research. Closer examination shows that Facebook helps young people build and maintain a network of friends, and that they are more likely to interact with one another offline if they are interacting online. Furthermore, narcissism is a trait that fuels certain types of Facebook use - not the other way around. Some of my own research has examined how young people use social technologies to develop a stable identity — a sense of self — in a way that was otherwise not possible before the advent of social media. In many ways, social media are actually a normative part of youth psychosocial development. 
Yet there it is - the message that something youth do all the time, something research shows is developmentally appropriate, is bad for them. We are telling youth that something that is a normal part of their existence is wrong. Recall the statements from the student-reporters: they were convinced that there were no benefits to social media use before seeing my data. What might these messages do to their psychological well-being? If you are told you are an addict, you might start believing it. "A lie told often enough becomes the truth." It's a feedback loop with public sentiment informing media and media informing public sentiment. Perhaps there's an added element of self-fulfilling prophecy - if you convince youth they don't want to interact offline, they'll show you they won't. Maybe if we approached youth from a youth normative instead of an adult normative perspective, they'd be more willing to share with us the realities of their online world.

How did we get here? Times have changed in the traditional media landscape. Before the Internet, there were a finite number of news outlets. There are now a seemingly endless number of places where people can get news. Reporters are pressured to have more people engage with their stories - their career depends on it. Added is the fact that reporters are not subject matter experts, meaning they typically aren't well versed in research methods. While my graduate students have learned the notion that "correlation doesn't mean causation," this doesn't hold true for reporters. If there is a relationship between Facebook use and narcissism, doesn't that mean that Facebook use is causing narcissism? Media literacy goes both ways. We need to have an educated populace that can make sense of and critically evaluate news, but we also need reporters who can sift out good research from bad and interpret findings for what they are.

This is no easy task. Indeed, it's easier to write a story that will generate reactions - and any reaction is better than none. If a reader is surprised, scared, or outraged, they are more likely to "like" the story and share it in their newsfeeds or tweet streams. We must move beyond this trap and support professional development that integrates knowledge of social science research. Perhaps the rapid emergence of social media caught us so off guard that we didn't realize we were dealing with a looking glass into our social world, not a different type of world altogether. As we move forward, it's important for us to examine the messages we send to youth, and to take a more balanced approach to reporting about new social and technological phenomena. We can do this by recognizing moral panic narratives and providing balance, not by focusing on the extreme progress narratives, but by speaking directly to young people's lived experiences.

\section{References / Resources / Links}

I Junco, R. (20 I 2). The relationship between frequency of Facebook use, participation in Facebook activities, and student engagement. Computers \& Education, 58( I), I62-I 7I. doi: Iо. I० I6/j. compedu.20 I I.08.004. http://blog.reyjunco.com/pdf/JuncoFacebookEngagementCAE2० I I. pdf 


\section{From Terrifying Turkeys To Flying Penguins: Empowering Students To Be Better Informed}

\section{Geanne Perlman Rosenberg \\ Baruch Gollege \\ Berkman Genter for Internet \& Society}

\section{Terrifying Turkeys}

In my first salaried, full-time job as a newspaper reporter at the New Haven Register, I covered the towns of Clinton and Killingworth, Connecticut. Often I would find stories during daily rounds visiting police headquarters and town hall, or while attending government meetings where I was performing the traditional role of watchdog journalist. Other times stories came to me, like the time an irate homeowner called me to complain that there were two pet turkeys terrorizing her street.

With no idea whether there was any factual basis to this seemingly farfetched tale of woe, I drove my blue Ford up Schnoor Road in Killingworth and pulled over to the side of the winding, wooded country lane. Sure enough, just as I got out of my car, I saw twin domestic turkeys charging toward me. Thinking I'd hit journalistic pay dirt, I happily barricaded myself in the car, and snapped some photos. I later snagged an interview with one of the turkeys' owners who said she was fed up with neighborhood complaints and that if she had any more trouble, her pet turkeys would find themselves "upside down and on a table." The story I thought might be a wild goose chase landed on the front page of the New Haven Register, along with my turkey photo.

Reimagine the turkey episode in the age of Facebook, YouTube and Twitter. The neighbors wouldn't need to locate and phone a newspaper reporter to cover the story. They could secure their own photos or, better yet, video, and publish their own story. It might go viral and, talking turkey, viewers might have no idea whether the foul fowl were a genuine neighborhood nuisance or a poultry prank.

\section{Flying Penguins}

This leads me in a roundabout way to flying penguins and the wonderful work of Youth and Media at the Berkman Center for Internet \& Society.

With the loss of the nearly exclusive ability to reach the public once held by news organizations, the general population now needs the same tools that were previously designated for journalists to employ so that the public can be informed with factual, newsworthy information.

I was long interested in examining the quality of information that was reaching the public. This was inspired by Professor Fred Friendly's focus on the role of the media and the media's impact on society, which I learned during classes I was fortunate to take with him at Bryn Mawr College and Columbia University in the I 980's. Further inspired by Stony Brook University's Center for News Literacy, and Alan Miller and his New Literacy Project, I planned the first ever high school news literacy summit at Baruch College in 20 I ०. A few of us collaborated on learning goals and here's what we developed: 
- "Informed citizens are essential to good government and free society.

- "There is a public value to sharing accurate, newsworthy information.

- "The Internet has changed how people receive news information and now people have to take a more active role in becoming well informed and sharing accurate information.

- "Accurate information is available online, but so is poor quality, misleading information.

- "The Internet makes it possible to independently fact check and verify information by looking at multiple information providers.

- "In assessing accuracy of information, it is important to consider who is providing it and their sources and whether the information includes verifiable facts and key perspectives as opposed to opinions and unsubstantiated conclusions.

- "To be well informed, one should get news from multiple outlets representing different perspectives.

- "It's important to follow a story over time to be able to trust the information.

- "Some news and information has a strong bias, and there are ways to recognize this.

- "One should be skeptical of information based purely on anonymous or biased sources.

- "It's important to be aware of one's own biases and assumptions and seek reliable information that challenges one's own views.

- "It is important to be open minded rather than having fixed opinions that can't be changed even with new facts."

In 20 I I, The McCormick Foundation, which had supported my work on the high school news literacy summit and the learning goals, introduced me to the Youth and Media team at the Berkman Center. Together, we brainstormed ways to reach students that would engage them with news literacy education.

Among the lessons learned were:

I. Fake news is a fun way to engage students in an effort to critically evaluate the information they encounter online. For us, the BBC Flying Penguins television report, a BBC and Telegraph April Fool's stunt, became an icebreaker for showing students information and asking them whether they believed it or not. We called upon them to use their electronic devices, such as smart phones or laptops, to assess the veracity of such information.

2. For teens, instruction on how to be an informed member of society or how to be news literate is not necessarily in and of itself engaging. That approach can be analogous to recommending broccoli to kids as a dietary staple. However, instruction on strategies that can help them be successful as students and in their careers is interesting and engaging for them and can accomplish the same goals of teaching students to be better informed and ultimately engaged, positive participants in civic life.

3. Sticking with the dietary theme, we learned through conversations with MIT educational games development experts at the Education Arcade that if you want to devise a game to teach kids to eat healthy foods, an engaging approach is a game that teaches the reverse, such as what foods one can eat to gain the most weight.

Accordingly, with these takeaways in mind, we co-developed a seminar entitled "Online Survival Skills for Students" that we have offered in various forms to teens in Turkey; undergraduate honors scholars at Columbia University; freshman at Baruch College; and high school students in New York City, Albu- 
querque, California, and South Side Chicago. The goals are: "To introduce students to the importance of protecting their own credibility in their online activities in order to succeed in school and in their careers; to introduce students to the importance of being and staying informed by finding credible sources of information, including news information; to provide students with some guidelines for finding, evaluating and verifying credible information; to provide students with some guidelines for being credible contributors to information through their social networking activities and Internet communications."

The work continues, strengthened by Youth and Media's inspiration and involvement, and thanks to major funding for my work from the Harnisch Foundation. In January 20 I 4, at Baruch College, Geneva Overholser and I co-directed a cross-disciplinary panel on standards and tools for identifying facts. The panel included a Noble Prize-wining scientist, law evidence professor, arts and business expert, and the New York Times public editor, moderated by Geneva. At a recent national news literacy summit in Chicago sponsored by the McCormick Foundation and organized by the Poynter Institute, educators from around the country met to strategize ways to make news literacy education more widely available. At Baruch College, I'm piloting a hybrid news and information literacy course that helps students become more discerning information consumers and contributors. This course builds upon lessons learned through collaboration with the Berkman Center's Youth and Media project.

The flying penguins and other information evaluation exercises continue to challenge students to evaluate what's true and what's not and to consider the quality of the information they receive and share.

As for the turkeys that terrorized Schnoor Road in the I 980's, given that the life expectancy for domestic turkeys is only about a decade, whether they have or haven't landed on a dinner table, their goose surely has been cooked.

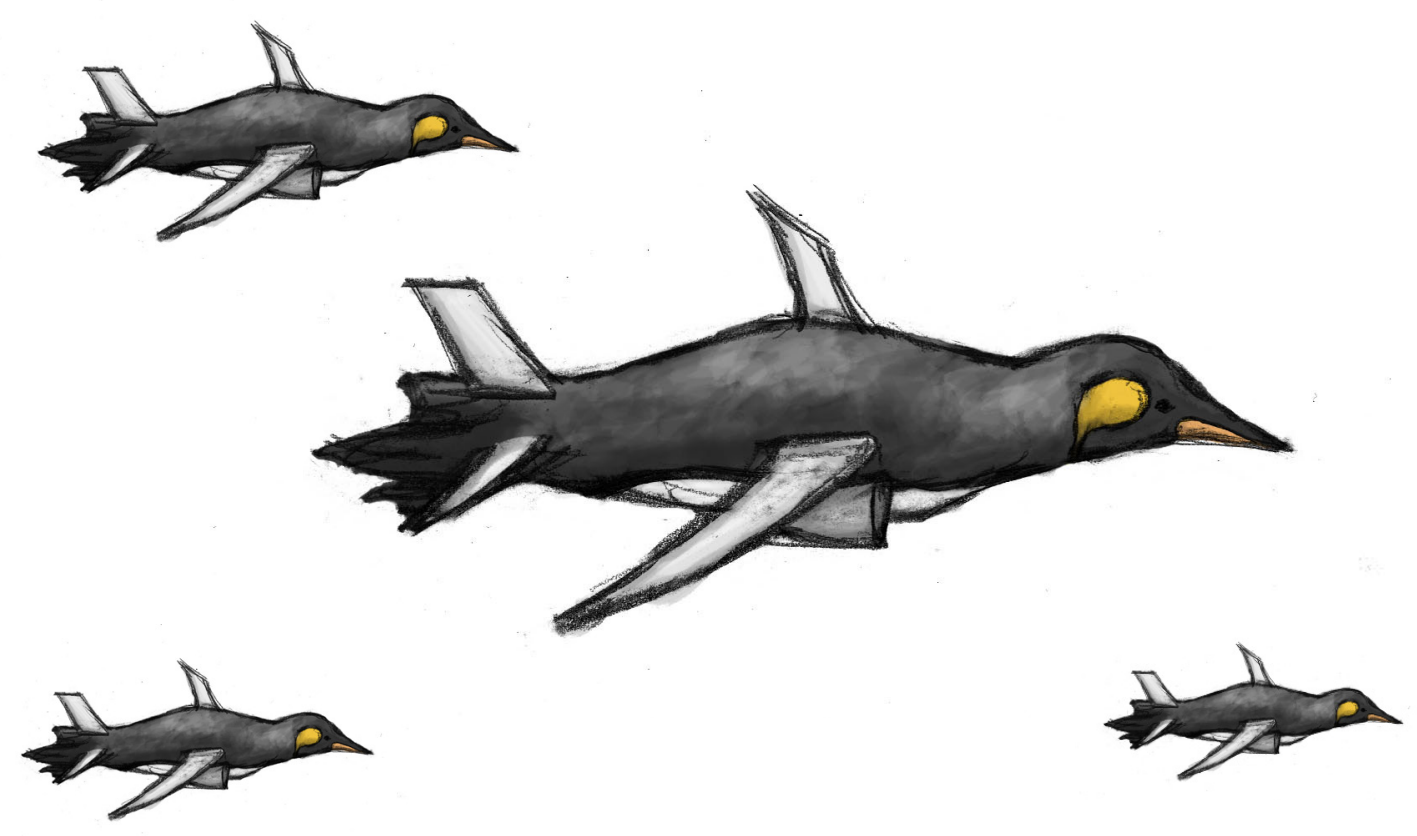




\section{Independent Journalism as Transformative Experience}

\section{Luis Felipe R. Murillo \\ Berkman Center for Internet \& Society}

The choices we make in our storytelling necessarily implicate potential stories that are left unsaid and unwritten, as there are numerous ways to narrate and interpret events. Composing the fabric of our collective memories, the unsaid and unwritten shape what we foreground and open possibilities for interpretation and collaboration in the production of news. Various forms of participation are rendered silent, invisible work in media production to the extent that some of the contributions are not even part of the scope of what counts as journalism. It is in the context of the invisible but valuable work around media production that we find opportunities to recreate the existing media with the contribution of new generations with their usage of new technologies.

A recent news piece on National Public Radio (NPR) on the usage of mobile phones by adolescents in the United States reports an interviewee who states she does not pay attention to her voice mail I : if it is not sent through text [messaging] or Facebook," she says, "it is not important." What is at stake for youth when it comes to electronic communication, information sharing, and new forms of Internet-based sociality is an open question for further research. One way to approach it would be to study the experience of news production and news literacy among those who avoid the news media. Thus, we could pose the question of what there is to learn about the relationship between certain social groups and the media from the perspective of those who are indirectly implicated in media production. The Youth and Media project at the Berkman Center for Internet and Society addressed this question by exploring different forms of relationships with the media among diverse social groups and advanced the concept of "semantic interoperability" 2 which allows for understanding what news and news literacy encompasses and how they are defined in particular contexts.

Providing interpretative keys for understanding news production and consumption, the Youth and Media project advanced knowledge about the experiential importance of news media through participation via indirect means. Reflecting upon my own trajectory, I can see how a small contribution to online media production gave me the opportunity to gather knowledge of a whole chain of production, distribution, and interpretation of news. As a teenager, I got involved with a local collective of the Independent Media Center (IMC) in my hometown in the South of Brazil. It was not a conscious choice whether to participate or not, I come to realize today. I did not plan to be part of the group; I was somehow chosen by own hobbies and interests. The IMC network had technical collectives, which were responsible for creating, managing, and teaching volunteers about its technical infrastructure, and I was drawn to it by my early experiences in computing. What I actually participated in, however, was not any kind of computing, but an experiment in socialization and alternative modes of production around Free Software technologies and Internet-based media production. This experience went a long way as I learned to reflect upon the news from a critical standpoint and read the news rather differently: exploring linkages between various news sources, examining them carefully for the articulation of arguments, and probing for what was left to be said and written about a particular event. Our motto, "don't hate the media, be the media," had a 
very important effect on a generation of media activists who turned to positive instead of negative modes of social critique. It was from this standpoint and from very specific technical affordances - the usage of the Internet as a medium of media for communication and articulation of a global IMC network - that I came to make sense of news media. And I was never alone in this collective venture as I shared similar experiences with volunteers around the world.

The IMC network represented an important locus of interaction and learning for many of us. From the late I 990's onward, the network grew in a distributed fashion with a very clear orientation toward autonomy of local collectives vis-à-vis the global network. Among volunteers, one could find individuals with quite diverse backgrounds. We had software developers, video editors, writers, political activists, network engineers and system administrators, professional and amateur journalists from different age groups, ethnic backgrounds, nationalities and walks of life. Public participation was allowed and encouraged on many levels: from volunteer contributions of short journalistic pieces to technical work for maintenance of servers and Internet services which allowed for indirect forms of engagement. Internet relay chat served for meetings of regional, national, and global scope as complementary means for collaborative work carried out at regular face-to-face meetings. I learned about what I could contribute to the project by attending face-to-face meetings and joining online conversations and decision-making processes. Through regular writing workshops that were offered by an experienced journalist to low-income communities in my hometown, I came to learn how to compose news articles. I also learned that I was a slow writer, therefore not suitable for dynamic, online journalistic work and decided to concentrate on technical tasks that were defined among other tech-inclined volunteers. For global events such as the World Social Forum, we had to wire local computer networks with Internet access for volunteers to work on their news pieces for local and global IMC collectives. We did not solely setup computers, however, we involved non-technical volunteers in the process, learning from each other and contributing to the editorial work.

Examining indirect forms of public participation can give access to important insights into the (subjective and objective) conditions for changing the perception and the production of news, even when negative perceptions are dominant. In order to provide an empirical foundation for the study of online media, Cortesi and Gasser 3 contributed a phenomenological approach to the experience of youth online with a focus on questions of diversity of sources, contents, and forms of exposure to online news. Their study resulted in a model for understanding the interplay between systemic, phenomenological, and linguistic approaches to the definition of news and news literacy. 4 Framing questions of access, co-production, and literacy along these three dimensions, the authors put into question simplistic causal explanations linking Internet use and news consumption. Events for ethical debate, for instance, can surface on sports news; questions of sexual violence and gender inequality may find the most interesting arena in the context of video gaming; major news broadcasting might find cascading effects as they get distributed through a combination of social media and offline social networks. 5 Among several other examples, we may find what we least expect in dispersed contexts as media traverses various domains of cultural practice. Out of several lessons we could learn from IMC in this regard, a major one concerns the worth of creating environments that are conducive to transformative experiences. Despite the invisibility of technical work, we can still tap into its transformative potential by involving young people in various capacities as media co-producers. We can facilitate participation with varying degrees of commitment in collaborative media projects with the goal of providing access to the inner workings of media discourse. Even if our social experiments do not help to create new journalists, reproducing existing systemic understandings and 
practices, they might help cultivate, at least, a more engaged and critical readership among the youth in the context of new media.

\section{References / Resources / Links}

I NPR. Please do not leave a message: Why millennials hate voice mail. http://www.npr.org/ blogs/alltechconsidered/20 I 4/ i /23/35830 I 467/please-do-not-leave-a-message-why-millennials-hate-voice-mail, accessed on I I $20 / 20$ I 4

2 Malik, M., Cortesi, S., \& Gasser, U. (20 I 3, October i 8). The Challenges of Defining 'News Literacy’. Berkman Center Research Publication No. 20 I 3-20. http://ssrn.com/abstract=23423 I 3

3 Cortesi, S., \& Gasser, U. (forthcoming). Youth online and news: A phenomenological view on diversity. International Journal of Communication.

4 Malik, M., Cortesi, S., \& Gasser, U. (2013, October I 8). The challenges of defining 'News Literacy’. Berkman Center Research Publication No. 20 I 3-20. http://ssrn.com/abstract=23423 I 3

5 Cortesi, S., Haduong, P., Gasser, U., \& Beaton, M. (20 г 3, October I 8). Youth news perceptions and behaviors online: How youth access and share information in a Chicago community affected by gang violence. Berkman Center Research Publication No. 20 I 3-1 9. http://papers.ssrn.com/ sol3/papers.cfm?abstract_id $=2342308$ 


\section{Publixphere - A Political Platform for Young Gitizens}

\section{Mayte Schomburg \\ Publixphere \\ Berkman Genter for Internet \& Society}

Publixphere ${ }^{\mathrm{I}}$ is a non-partisan and independent platform for politically interested young Germans. The platform delivers quality information around political issues and with a safe space on which to debate these issues online and offline. It is run by the non-profit membership association Publixphere e.V, and funded exclusively through donations. Publixphere operates under the assumption that the notion of politics is changing, and acknowledges an oft-lamented lack of political engagement among young citizens. This gap may be the result of a lack of political interest, but interest in politically relevant issues may be captured and channeled into engagement if a link is established between young citizens and political decision-makers and experts.

Communicating politics in a way that speaks to both youth and young adults is crucial for encouraging their involvement in political discussion. Publixphere seeks to complement the wealth of youth engagement initiatives by providing young adults with an open forum for political discussion. In many ways, the state of a democracy can be measured by the quality of its public sphere: ideally, free public discussion gives rise to a wealth of issues, both political and nonpolitical, and provides an arena in which relevant issues are translated into the political public sphere. The idea is for politically relevant issues to be picked up by media and political actors in the public debate, so that political alternatives may be identified and publicly debated. With regard to young citizens, this also means that their voices find resonance within this sphere. Today, the opinions and discussions among young citizens often remain detached from "established" politics. At Publixphere we believe that it is worthwhile to leverage young citizens' interest in issues and to actively facilitate dialogue around these issues with political decision-makers, experts, interest groups and other actors of interest to a debate. The goal is to not only provide a forum for information around issues, but also to make the young citizens' voices heard.

Geared specifically towards politically interested, yet not necessarily engaged, and predominantly young citizens, Publixphere's aim is to provide valuable information around issues. Just like a news outlet, Publixphere is focused on delivering quality information to its users. Rather than providing daily or weekly news, however, the focus lies on users setting the agenda: On Publixphere.net, any registered user can start a discussion around any issue that (s)he finds politically relevant. The Publixphere-community listens, adds to and promotes individual ideas through discussion, by voting on individual contributions, and by linking relevant information already available in other realms of the Net.

Since the privacy of our users is of utmost concern to us, Publixphere allows for different degrees of anonymity online. While "regular" users tend to use some kind of pseudonym, for instance, politicians and organizations tend to use their clear names - verified by us and made visible vis-à-vis our users through badges indicating political party, name of the institution or the like. A third category of users uses a mix 
between these options. For instance, the young chapter of a (German) foreign policy network allows their members to use pseudonyms as well as - again after verification - a badge indicating their belonging to this group. For many with that network, this is the only way to publicly discuss politics online as they might be working for members of parliament, in ministries or other politically sensitive positions. Conversely, having some sort of indication of the respective users' expertise in a specific field (in this case foreign policy) is helpful for other participants as well as for passive readers of the respective discussions.

Those issues that find the most traction within the community enter an editorial process. This entails a non-partisan editor compiling relevant background information and bringing in expert voices to answer questions such as the following: what is the current status of a debate, what are the positions of different political parties, which institutions take part in the debate and how is it possible to get engaged? What is the European dimension? If the discussion spans different countries: how does the debate in Poland relate to that in Germany or Greece? As discussions develop and new questions arise, background texts evolve. Topics range from the Transatlantic Trade and Investment Partnership (TTIP) to the crisis in Ukraine, to media criticism and the effects of state surveillance.

The website publixphere.net undoubtedly forms the backbone of Publixphere's activities, but complementing online discussions through face-to-face exchanges is key. This is significant in several respects: for building trust amongst Publixphere and its users as well as amongst users and decision-makers, for adding a personal layer to virtual discussions, and for empowering individual users to enter into a face-toface discussion with decision-makers as experts in their own right. We often collaborate with foundations or universities in organizing or facilitating events in which questions from Publixphere's online discussions are taken up. Regular face-to-face community meetings are also key to Publixphere's activities. In all of our offline activities, the goal is to take up issues and questions that came up in online discussions, and to solicit feedback to the online community.

In conclusion, Publixphere is committed to providing young citizens with targeted information around political issues not only by providing editorial content, but also by facilitating discussions amongst young citizens and political decision-makers. By enabling users to start their own discussions on political topics and commenting on others' ideas, and by providing targeted editorial support, Publixphere allows users to contribute to the overall public dialogue and to set the agenda for an open discourse. In introducing other relevant stakeholders into the online discussion, Publixphere organizes a response young citizens usually lack. We hope to show them that their input makes a difference.

\section{References / Resources / Links}

I Publixphere. https://publixphere.net 
